\title{
C242T polymorphism of P22phox gene of the nox: a putative pathological risk factor for stroke in Kashmiri population
}

\begin{abstract}
Background and purpose: NADPH oxidase (Nox) is a multicomponent enzyme responsible for the generation of reactive oxygen species (ROS). The p22phox is a key component of the cytochrome b558 of Nox and is essential for the activation of this enzyme, which by generating reactive oxygen species (ROS) is involved in the pathogenesis of many inflammatory diseases. The Nox-mediated excessive ROS production can damage tissue and represents an important cause of injury in many chronic inflammatory disorders including rheumatoid arthritis, atherosclerosis, lung injury and inflammation-associated cancer. An intensive expression of the $p 22 p h o x$ has been reported in human atherosclerotic arteries. However, studies on the association of the $\mathrm{C} 242 \mathrm{~T}$ polymorphism in the $p 22 p h o x$ gene with cerebrovascular disease (CVD) have produced conflicting results, and the relation of this polymorphism with CVD is not well known in a population with acquired risk factors enhancing the Nox-dependent superoxide production. We investigated the relevance of C242T polymorphism of p22phox gene to stroke, the maiden study directed in ethnic Kashmiri subjects.
\end{abstract}

Methods: The study included 100 cases suffering from stroke (both ischemic and hemorrhagic stroke) and 120 controls. DNA was isolated from peripheral leukocytes and the genomic analysis of C242T polymorphism was done by PCR-RFLP.

Results: We found $\mathrm{T}$ allele frequency of $38 \%$ in cases and $14 \%$ in controls $(\mathrm{p}<0.0001)$. Hemorrhagic stroke $\mathrm{T}$ allele frequency was $41 \%(\mathrm{p}<0.0001)$ and Ischemic stroke $\mathrm{T}$ allele frequency was $34 \%(\mathrm{p}<0.0001)$

Conclusion: The presence of $\mathrm{T}$ allele was associated with higher risk of stroke. The prevalence of T allele was significantly higher in stroke patients $(\mathrm{p}<0.0001)$ irrespective of type which demonstrates that $\mathrm{C} 242 \mathrm{~T}$ polymorphism of $p 22 p h o x$ gene plays an important role in the stroke in Kashmiri population.

Keywords: p22phox gene, Stroke, NADPH oxidase, C242T polymorphism
Volume I Issue 4 - 2014

\author{
Ankush Sharma,' Shiekh Saleem, ${ }^{2}$ Sawan \\ Verma, ${ }^{2}$ Dil- Afroze ${ }^{3}$ \\ 'Department of General Medicine, Sher-I-Kashmir Institute of \\ Medical Sciences, India \\ 2Department of Neurology, Sher-I-Kashmir Institute of Medical \\ Sciences, India \\ ${ }^{3}$ Department of Immunology \& Molecular Medicine, Sher-I- \\ Kashmir Institute of Medical Sciences, India
}

\begin{abstract}
Correspondence: Dil-Afroze, Department of Immunology \& Molecular Medicine, Sher-I-Kashmir Institute of Medical Sciences, Srinagar- 191, India, Tel 9419115173,

Email afrozedil@gmail.com
\end{abstract}

Received: July 18, 2014 | Published: July 31, 2014
Abbreviations: CVA, Cerebro Vascular Accident; ROS, Reactive Oxygen Species; VSMCs, Vascular Smooth Muscle Cells; SKIMS, Sher-I-Kashmir Institute of Medical Sciences

\section{Introduction}

Stroke is a global health problem; it is the second commonest cause of death and fourth leading cause of disability worldwide. ${ }^{1}$ In developed countries, stroke is the first leading cause for disability, second leading cause of dementia and third leading cause of death. ${ }^{2}$ According to a worldwide assessment, roughly 2 crore people each year will suffer from stroke and of these 50 lakh will not survive. ${ }^{3}$ Out of this, low and middle-income countries account for $85.5 \%$ of total stroke deaths worldwide and the number of disability-adjusted life years in these countries is projected to be seven times that in high-income countries. ${ }^{4}$ In India, the ICMR evaluations put the stroke contributed deaths at $41 \%$ and disability adjusted life years amongst the non-communicable diseases at $72 \% .{ }^{5}$ Overall in India, the adjusted annual incidence per 100,000 persons of stroke is 124 in rural area ${ }^{6}$ and 145 in urban area. ${ }^{7}$ Reliable morbidity and mortality estimates for stroke from the North-Indian state of Jammu \& Kashmir are limited and are confined to studies that suffer from frequent bias, small and variable sample sizes, and inconsistent diagnostic criteria. Nevertheless, the only documented prevalence rate reported that the crude and age adjusted prevalence rate was 143 and 244 per 100,000 of population. ${ }^{8}$
A stroke, or cerebrovascular accident (CVA), is a clinical syndrome with the rapid loss of brain function due to disturbance in the blood supply to the brain. The WHO clinically defines stroke as 'the rapid development of clinical signs and symptoms of a focal neurological disturbance lasting more than 24 hours or leading to death with no apparent cause other than vascular origin'. ${ }^{9}$ Based on its pathophysiology, it can be due to ischemia (lack of blood flow) caused by blockage (thrombosis, arterial embolism), or a hemorrhage caused either by subarachnoid bleeding from one of the brain's arteries into the brain tissue or intra-cerebral arterial bleeding in the space between meninges. Ischemic stroke account for $50 \%-85 \%$ while hemorrhagic strokes comprise of $1 \%-7 \%$ due to subarachnoid bleeding and $7 \%$ $27 \%$ due to intra-cerebral arterial bleeding of all strokes worldwide. ${ }^{10}$ The effects of a stroke depend on the site and severity of brain injury. A very severe stroke can cause sudden death.

NADPH oxidase/Nox is a multicomponent enzyme responsible for the generation of reactive oxygen species (ROS); the catalytic core-Nox 2 of the NADPH oxidase first identified in phagocytes along with several homologues (Nox1 to Nox5, Duox1 and Duox2) characterized in various non-phagocytic cells have distinct features in tissue distribution, expression regulation, and physiological functions. In the resting state, Nox2 associated p22phox to the membrane; both proteins constituting the cytochrome b558. Upon stimulation, the cytosolic components (p47phox, p67phox, p40phox and Rac1/2) of the NADPH oxidase are recruited to the membrane where they assemble with the cytochrome b558 to form the active enzyme. ${ }^{11}$ 
Oxidative stress plays critical roles in cardiovascular physiology and in the pathogenesis of vascular disease. ${ }^{12}$ Vascular and cardiac tissues are rich sources of reactive oxygen species (ROS), including superoxide $\left(\mathrm{O}_{2}\right)$, hydrogen peroxide $\left(\mathrm{H}_{2} \mathrm{O}_{2}\right)$, and nitric oxide $\left(\mathrm{NO}_{2}\right)$. Virtually every cell type in the vascular wall has been shown to produce and be regulated by ROS. ${ }^{13,14}$ The ischemic brain reperfusion produces a massive increase in oxygen free radicals triggering exacerbate ischemic injury. Initial work identified xanthenes oxidase as a prime source of endothelium-dependent $\mathrm{O}_{2}$-production. ${ }^{15,16}$ Superoxide dismutase and catalase- the antioxidant enzymes shrink ischemic damage as over expression of superoxide dismutase in transgenic mice are shown to extend protection to neurons from ischemic/ reperfusion injury. ${ }^{17-20}$

While there are diverse sources of free radicals generation, numerous distinct oxygen species from neutrophils and phagocytes that are observed in ischemic brain tissue, are primarily able to produce oxygen free radicals and thus have been associated with ischemic injury. ${ }^{21} \mathrm{NADPH}$ oxidase-mediated ROS production are involved not only in the killing of invading microorganisms but are also used as a second messenger for signal transduction in the endothelium and plays a major role in mediating ischemic injury in the brain. ${ }^{22}$ However, an excessive ROS production can damage tissue and represents an important cause of injury in many chronic inflammatory disorders. Given the importance of the Nox in the pathophysiology of inflammatory diseases, it appears that its activity needs to be firmly controlled by different mechanisms that ensure an appropriate physiological regulation.

$\mathrm{NAD}(\mathrm{P}) \mathrm{H}$ oxidase is present in vascular smooth muscle cells (VSMCs) and endothelial cells. A component of Nox, p22phox is expressed in VSMCs and serves as a critical component of regulating vascular hypertrophy, ${ }^{23}$ and seems to be a major source of superoxide production in animal models of vascular disease $\mathrm{e}^{24}$ and in human atherosclerosis..$^{25,26}$ The p22phox subunit of the Nox multi-subunit enzyme complex is required for oxidase activity in smooth muscle cells, and is expressed in human coronary arteries. ${ }^{27}$ Much interest has been focused on the possible association of polymorphisms in the $C Y B A$ gene, which encodes $p 22 p h o x$, with atherosclerosis. ${ }^{28}$ A putatively functional polymorphism of the $C Y B A$ gene encoding the $p 22$ phox subunit of Nox has been described; the C242T variant results in the substitution of tyrosine for histidine within one of the two haem-binding sites that are thought to be essential for the stability of the protein. ${ }^{29}$

Ethnicity is an important determinant of genetic polymorphisms. Distribution of allelic variation in the gene for p22phox has been established for several ethnic groups in the world. The present study was sought to study the distribution of $p 22$ phox $\mathrm{C} 242 \mathrm{~T}$ polymorphism and its relevance to stroke in a community based sample drawn from ethnic north Indian population of Kashmir valley.

\section{Materials and methods}

\section{Subject characteristics}

The present study was conducted at Sher-i-Kashmir Institute of Medical Sciences (SKIMS), Srinagar. The study was approved by Institutional Ethics committee and written consent was taken from each patient. The participants included a total of 220 ethnic Kashmiri subjects comprising of 100 diagnosed stroke patients (without any modifiable risk factor) and 120 age and gender matched controls. One hundred above-mentioned stroke patients of both genders of age $>45$ years were enlisted for the present study except those with presence or history of hypertension, diabetes mellitus, hyperlipidaemia, smoking, known or suspected coronary/ peripheral vascular disease, any significant chronic medical or surgical condition any acute illness within previous two weeks, atrial fibrillation or significant carotid stenosis. Routine laboratory investigations like complete haemogram with ESR, serum chemistry including plasma glucose, complete lipid profile, KFT, LFT, serum uric acid were measured on Olympus AU640 automated analyser. Electrocardiogram, Chest Roentogenogram, Neck Vessel Doppler and Echocardiography were also done.

\section{Genotyping analysis}

$5 \mathrm{ml}$ of peripheral blood was obtained from each subject and total genomic DNA was extracted using Phenol-Chloroform method. The 353-bp target region of $p 22 p h o x$ gene was amplified by polymerase chain reaction with sense primer 5' -TGCTTGTGGGTAAACCAAGG3'and antisense primer 5' -GGAAAAACACTGAGGT AAGTG-3' in a $25 \mu 1$ reaction volume. The PCR reaction consisted of an initial denaturation step of 2 minute at $95{ }^{\circ} \mathrm{C}$, followed by 35 cycles of 3 minutes at $95{ }^{\circ} \mathrm{C}$ (denaturation), 1 minute at $56{ }^{\circ} \mathrm{C}$ (annealing) and 7 minutes at $72{ }^{\circ} \mathrm{C}$ (extension) and a final extension of 7 minutes at $72{ }^{\circ} \mathrm{C}$. The $353 \mathrm{bp}$ PCR product was cleaved with $1 \mu 1$ Rsa I restriction enzyme for $18-24 \mathrm{hrs}$ at $37{ }^{\circ} \mathrm{C}$. The restriction fragments were separated on a $2.5 \%$ agarose gel and visualized under a geldocumentation system. Digestion of the amplicon yield bands of $353 \mathrm{bp}$ in CC homozygous, 193bp \& 160bp bands in TT homozygous and all the three 353bp, 193bp and 160bp in CT heterozygous.

\section{Statistical analysis}

Statistical Package for Social Sciences (SPSS), version 16.0 for Windows (Chicago Illinois, USA) was used for data analysis. Descriptive statistics are presented as Mean \pm SD or frequency unless indicated otherwise. Relevant statistical details like Chi-square trend analysis, $\mathrm{p}$ values and Cramer's $\mathrm{V}$ tests have been included. $\mathrm{p}$ value of $<0.05$ was taken as the criterion of statistical significance.

\section{Results}

The participants in this study included a total of 220 subjects. One hundred patients suffering from stroke (both Ischemic and Hemorrhagic stroke) and 120 healthy age/gender matched controls. Mean age of the subjects was $55.18 \pm 6.825$. In our study, patients with stroke had higher values of ESR $(p<0.001)$ and SGOT $(p=0.003)$, while as lower $\mathrm{Na}^{+}(\mathrm{p}=0.018)$ and $\mathrm{K}+(\mathrm{p}=0.003)$ levels. The $\mathrm{T}$ allele frequency was 0.14 in controls and 0.38 in cases (Table 1). CC genotype was present in $96 \%$ of controls and $35 \%$ of cases. We studied allelic variation in both Hemorrhagic as well as Ischemic stroke patients. Hemorrhagic subjects exhibited higher frequency of T allele (0.41) in comparison to Ischemic subjects $(0.34)$.

\section{Discussion}

This is the first documented report of allelic variation in $p 22$ phox component of superoxide generating enzyme- Nox in the community based sample from Indian subcontinent. In the present study, presence of $\mathrm{T}$ allele was associated with higher risk of both hemorrhagic and ischemic stroke. The genotype frequency of $\mathrm{T}$ allele in our population is higher than Japanese and Chinese populations ${ }^{29-31}$ but similar to that reported in various other populations. ${ }^{25,32}$ The baseline characteristics of subjects were similar between the genotypes (CC, CT and TT) except ESR and $\mathrm{Na}^{+}$levels (Table 2). Trend towards higher ESR was seen both in hemorrhagic stroke $(p p<0.001)$ and Ischemic stroke $(\mathrm{p}<0.001)$. This finding is consistent with previous study showing relation between ESR and risk of developing coronary heart disease. ${ }^{33}$ Trend towards higher SGOT was also observed in both 
hemorrhagic stroke $(p=0.003)$ and Ischemic stroke $(p p<0.015)$. The presence of $\mathrm{C}$ allele has been shown to have a protective effect against stroke in our population. Presence of T allele correlates directly with both hemorrhagic and ischemic stroke in our population. Our findings depict substantial statistical significant than the study on Japanese stroke patients ${ }^{34} \mathrm{and} /$ or various genetic studies conducted on ischemic stroke patients in India. ${ }^{35,36}$ Our study is indicative of a role of T allele in the pathogenesis of stroke in ethnic Kashmiri population of north India. Further, this is the first study which has explored allelic variations in the gene for p22phox component of the superoxide- generating enzyme after excluding all modifiable risk factors for stroke patients. However, higher sample size needs to be studied in order to further corroborate our results. Also, more SNPs need to be evaluated to rule out the possibility of linkage equilibrium between these SNPs and one or more other functional polymorphisms. On the other hand, the present study avoids several limitations that might have affected the interpretation of many of the previous studies as we excluded all modifiable risk factors for hemorrhagic and ischemic stroke and also excluded stroke in young in which other factors could have convoluted their findings.

Table I Genotype and allele frequencies of p22PHOX $(\mathrm{C}>\mathrm{T})$ polymorphism in stroke patients and controls

\begin{tabular}{|c|c|c|c|c|c|}
\hline Subjects (n) & CC (n) \% & CT (n) \% & TT (n) \% & P value ( $\chi 2$-trend) (Cramer's V) & $\mathbf{T}$ allele Frequency \\
\hline Controls (I20) & $96(80)$ & $14(11.66)$ & $10(8.33)$ & \multirow{2}{*}{$<0.0001(49.88)[0.476]$} & 0.14 \\
\hline Cases $(100)$ & $35(35)$ & $53(53)$ & $12(12)$ & & 0.38 \\
\hline Ischemic (43) & I8 (4I.86) & $20(46.5 \mathrm{I})$ & $5(11.62)$ & $<0.0001(25.38)[0.395]$ & 0.34 \\
\hline Hemorrhagic (57) & $17(29.82)$ & $33(57.89)$ & $7(12.28)$ & $<0.0001(46.97)[0.515]$ & 0.41 \\
\hline
\end{tabular}

Table 2 Clinical features among subjects with different genotypes

\begin{tabular}{|c|c|c|c|c|}
\hline Variable & CC & CT & TT & $P$ value \\
\hline Age & $54.32 \pm 5.68$ & $55.63 \pm 8.53$ & $58.43 \pm 2.37$ & 0.28 \\
\hline $\mathrm{Hb}$ & $13.03 \pm 1.12$ & $|2.66 \pm| .5 \mid$ & $13.77 \pm 0.73$ & 0.08 \\
\hline НCT & $4 \mid .21 \pm 5.89$ & $38.7 I \pm 9.03$ & $41.34 \pm 3.06$ & 0.23 \\
\hline ESR & $12.34 \pm 10.60$ & $21.35 \pm 13.20$ & $25 \pm 10.73$ & 0.000 \\
\hline SGOT & $33.30 \pm 20.70$ & $36.25 \pm 12.89$ & $31.14 \pm 5.87$ & 0.63 \\
\hline $\mathrm{Na}^{+}$ & $136.24 \pm 4.38$ & $134.22 \pm 4.97$ & $132.36 \pm 4.23$ & 0.03 \\
\hline $\mathrm{K}^{+}$ & $4.82 \pm 0.36$ & $3.34 \pm 0.47$ & $3.52 \pm 0.37$ & 0.3 \\
\hline
\end{tabular}

\section{Acknowledgments}

None.

\section{Conflicts of interest}

None.

\section{References}

1. Strong K, Mathers C, Bonita R. Preventing stroke: saves lives around the world. Lancet Neurol. 2007;6(2):182-187.

2. Taylor FC, Kumar SK. Stroke in India Factsheet. 2012

3. Dalal P, Bhattacharjee M, Vairale J, et al. UN millennium development goals: can we halt the stroke epidemic in India? Ann Indian Acad Neurol. 2007;10(3):130-136.

4. Mathers CD, Lopez AD, Murray CJL. The burden of disease and mortality by condition: data, methods and results for 2001. In: Lopez AD, Mathers CD, Ezzati M, Jamison DT, Murray CJL (Eds.), Global burden of disease and risk factors. Washington (DC), USA. 2006.

5. Indian Council for Medical Research (ICMR). Stroke. In: Assessment of the burden of non-communicable diseases: Final project report. Indian Council of Medical Research, New Delhi, India. 2004;pp.18-22.

6. Bhattacharya S, Saha SP, Basu A, et al. A 5 year prospective study of incidence, morbidity and mortality stroke profile on stroke in a rural community of Eastern India. J Indian Med Assoc. 2005;103(12):655659.

7. Das SK, Banerjee TK, Biswas A, et al. A prospective community based study of stroke in Kolkata, India. Stroke. 200738(3):906-910.

8. Razdan S, Koul RL, Motta A, et al. Cerebrovascular disease in rural Kashmir, India. Stroke. 1989;20(12):1691-1693.

9. World Health Organisation. Preventing chronic diseases: a vital investment. Geneva, Switzerland. 2005.
10. Feigin VL, Lawes CM, Bennett DA, et al. Worldwide stroke incidence and early case fatality reported in 56 population based studies: a systematic review. Lancet Neurology. 2009;8(4):355-369.

11. El-Benna J, Dang PM, Gougerot-Pocidalo MA, et al. Phagocyte NADPH oxidase: a multicomponent enzyme essential for host defenses. Arch Immunol Ther Exp. 200553(3):199-206.

12. Kojda G, Harrison D. Interactions between NO and reactive oxygen species: pathophysiological importance in atherosclerosis, hypertension, diabetes and heart failure. Cardiovasc Res. 199943(3):562-571.

13. Griendling KK, Ushio-Fukai M. NADH/NADPH oxidase and vascular function. Trends Cardiovasc Med. 1997;7(8):301-307.

14. Suzuki YJ, Ford GD. Redox regulation of signal transduction in cardiac and smooth muscle. JMol Cell Cardiol. 199931(2):345-353.

15. Phan SH, Gannon DE, Varani J, et al. Xanthine oxidase activity in rat pulmonary artery endothelial cells and its alteration by activated neutrophils. Am J Pathol. 1989;134(6):1201-1211.

16. Zweier JL, Kuppusamy P, Lutty GA. Measurement of endothelial cell free radical generation: evidence for a central mechanism of free radical injury in postischemic tissues. Proc Natl Acad Sci U S A. 1988;85(11):4046-4050.

17. Liu TH, Beckman HS, Freeman BA, et al. Polyethylene glycolconjugated superoxide dismutase and catalase reduce ischemic brain injury. Am J Physiol. 1989256(2 pt 2):H589-H593.

18. Imaizumi S, Woolworht V, Fishman RA, et al. Liposome-entrapped superoxide dismutase reduces cerebral infarction in cerebral ischemia in rats. Stroke. 1990;21(9):1312-1317.

19. He YY, HSU CY, Ezrin AM, et al. Polyethylene glycol-conjugated superoxide dismutase in focal cerebral ischemia reperfusion. Am $J$ Physiol. 1993;265(1 Pt 2): $\mathrm{H}_{2} 52-\mathrm{H}_{2} 56$.

20. Chan PH. Role of oxidants in ischemic brain damage. Stroke. 1996;27(6):1124-1129. 
21. Del Zoppo GJ, Schmid-Schonbein GW, Mori E, et al. Polymorphonuclear leukocytes occlusion and reperfusion in baboon. Stroke. 1991;22(10):1276-1283.

22. Walder CE, Green SP, Darbonne WC, et al. Ischemic stroke injury is reduced in mice lacking a functional NADPH oxidase. Stroke. 199728(11):2252-2258

23. Ushio-Fukai M, Zafari AM, Fukui T, et al. p22phox is a critical component of the superoxide-generating NADH/NADPH oxidase system and regulates angiotensin II-induced hypertrophy in vascular smooth muscle cells. J Biol Chem. 1996;271(38):23317-23321.

24. Warnholtz A, Nickenig G, Schulz E, et al. Increased NADH-oxidase mediated superoxide production in the early stages of atherosclerosis: evidence for involvement of the renin- angiotensin system. Circulation. 1999;99(15):2027-2033.

25. Guzik TJ, West NEJ, Black E, et al. Vascular superoxide production by $\mathrm{NAD}(\mathrm{P}) \mathrm{H}$ oxidase: association with endothelial dysfunction and clinical risk factors. Circ Res. 2000;86(9):E85-E90.

26. Griendling KK, Sorescu D, Ushio-Fukai M. NAD(P)H oxidase: role in cardiovascular biology and disease. Circ Res. 2000;86(5):494-501.

27. Azumi $\mathrm{H}$, Inoue $\mathrm{N}$, Takeshita $\mathrm{S}$, et al. Expression of $\mathrm{NADH} /$ NADPH oxidase p22phox in human coronary arteries. Circulation. 1999100(14):1494-1498.

28. Inoue N, Kawashima S, Kanazawa K, et al. Polymorphism of the $\mathrm{NADH} / \mathrm{NADPH}$ oxidase $p 22$ phox gene in patients with coronary artery disease. Circulation. 1998;97(2):135-137.
29. Redon J, Oliva MR, Tormos C, et al. Antioxidant activities and oxidative stress by-products in human hypertension. Hypertension. 2003;41(5):1096-1101.

30. Pattit AI, Wong RK, Lee V, et al. Increased free radical production in hypertension due to increased expression of the NADPH oxidase subunit p22(phox) in lymphoblast cell lines. J Hypertens. 2002;20(4):677-683.

31. Shimo-Nakanishi Y, Hasebe T, Suzuki A, et al. Functional effects of $\mathrm{NAD}(\mathrm{P}) \mathrm{H}$ oxidase p22phox $\mathrm{C} 242 \mathrm{~T}$ mutation in human leukocytes and association with thrombotic cerebral infarction. Atherosclerosis. 2004;175(1):109-115.

32. Gardemann A, Mages P, Katz N, et al. The p22phox A640G gene polymorphism but not the $\mathrm{C} 242 \mathrm{~T}$ gene variation is associated with coronary heart disease in younger individuals. Atherosclerosis. $1999 ; 145(2): 315-323$

33. Andresdottir MB, Sigfusson N, Sigvaldason H, et al. Erythrocyte sedimentation rate, an independant predictor of coronary heart disease in men and women: The Reykjavik Study. Am J Epidemol. 2003;158(9):844-851.

34. Ito D, Murata M, Watanabe K, et al. C242T polymorphism of NADPH oxidase p22 PHOX gene and ischemic cerebrovascular disease in the Japanese population. Stroke. 200031(4):936-939.

35. Munshi A, Sultana S, Koul S, et al. Angiotensin-converting enzyme insertion/ deletion polymorphism and the risk of ischemic stroke in a south Indian population. J Neurol Sci. 2008272(1-2):132-135.

36. Munshi A, Koul S, Aliya N, et al. Prothrombin gene G20210A mutation is not a risk factor of ischemic stroke in a south Indian Hyderabadi population. Thromb Res. 2009124(2):245-247. 